\title{
Brief Report \\ Metastatic Group 3 Medulloblastoma in a Patient With Tuberous Sclerosis Complex: Case Description and Molecular Characterization of the Tumor
}

\author{
Romina Moavero, $\mathrm{MD}_{1}{ }^{1,2}$ Valentina Folgiero, $\mathrm{MD}, \mathrm{PhD}^{3 *}$ Andrea Carai, MD, $\mathrm{PhD},{ }^{4}$ Evelina Miele, $\mathrm{MD}, \mathrm{PhD},{ }^{5,6}$ \\ Elisabetta Ferretti, MD,PhD, ${ }^{5}$ Agnese Po, $\mathrm{PhD}^{5}{ }^{5}$ Francesca Diomedi Camassei, $\mathrm{MD}, \mathrm{PhD}^{7}$ \\ Francesca Romana Lepri, PhD, ${ }^{8}$ Federico Vigevano, MD, ${ }^{1}$ Paolo Curatolo, $\mathrm{MD}_{1}{ }^{2}$ Massimiliano Valeriani, $\mathrm{MD},{ }^{1}$ \\ Giovanna S. Colafati, MD, ${ }^{9}$ Franco Locatelli, MD, ${ }^{3,10}$ Assunta Tornesello, $\mathrm{MD}^{11}$ and Angela Mastronuzzi, $\mathrm{MD}^{3}$
}

Medulloblastoma is the most common pediatric brain tumor. We describe a child with tuberous sclerosis complex that developed a Group 3, myc overexpressed, metastatic medulloblastoma (MB). Considering the high risk of treatment-induced malignancies, a tailored therapy, omitting radiation, was given. Based on the evidence of mammalian target of rapamycin mTORC, mTOR Complex; RAS, Rat sarcoma; RAF, rapidly accelerated fibrosarcoma (mTOR) path- way activation in the tumor, targeted therapy was applied resulting in complete remission of disease. Although the PI3K/AKT/mTOR signaling pathway plays a role in MB, we did not find TSC1/TSC2 (TSC, tuberous sclerosis complex) mutation in our patient. We speculate that a different pathway resulting in mTOR activation is the basis of both TSC and MB in this child; H\&E, haematoxilin and eosin; Gd, gadolinium. Pediatr Blood Cancer @ 2015 Wiley Periodicals, Inc.

Key words: medulloblastoma; mTOR; TSC1/2

\section{INTRODUCTION}

Medulloblastoma (MB) is the most common malignant central nervous system (CNS) tumor of childhood. Current multimodal treatment of $\mathrm{MB}$ has led to a 5-year overall survival of about $87 \%$ for average-risk and $70 \%$ for high-risk patients.[1] However, prognosis remains poor for patients with recurrent MB. Recently, four molecular subgroups have been described (wingless/integrated [WNT], sonic hedgehog [SHH], Group 3, and Group 4) that differ in their demographics, transcriptomes, somatic genetic events and clinical outcomes.[2]

CNS malignancies can be associated with different neurogenetic syndromes, including tuberous sclerosis complex (TSC). TSC is an autosomal dominant neurocutaneous disease affecting about one in 6,000 newborns, and characterized by the presence of widespread hamartomas. CNS involvement results in a high rate of epilepsy, mental retardation, and neuropsychiatric disorders.[3] This disease has a variable expression ranging from severe mental retardation, intractable seizures, and extensive organ involvement to patients presenting few and asymptomatic hamartomas, normal cognitive levels, and no seizures. Mammalian target of rapamycin (mTOR) overactivation is the key finding in TSC.[4] Experimental findings suggest that inactivation of TSC genes can cooperate with $\mathrm{SHH}$ signaling to drive tumor growth through mTOR-dependent translation machinery.[5] Although patients with TSC are at increased risk of developing CNS malignancies,[6] an association with MB has never been described.

\section{RESULTS}

Our patient was born at term after the first uneventful pregnancy to healthy unrelated parents. At 14 months of age, she began to present focal seizures. Magnetic resonance imaging (MRI) revealed the presence of several cortico-subcortical tubers associated with small subependymal lesions, leading to a definite diagnosis of TSC according to revised diagnostic criteria.[7] Further investigation revealed the presence of a single ash-leaf hypomelanotic macule and cardiac rhabdomyomas.
Additional Supporting Information may be found in the online version of this article.

Abbreviations: CNS, central nervous system; EEG, electroencephalogram; EGFL11, alias of EYS: eyes shut homolog; GABRA5, gamma-aminobutyric acid (GABA) A receptor, alpha 5; Gd, gadolinium; H\&E, haematoxilin and eosin; IMPG2, interphotoreceptor matrix proteoglycan 2; LC/A, large cell/anaplastic; MAB21L2, mab-21-like 2; MB, medulloblastoma; MRI, magnetic resonance imaging; mTOR, mammalian target of rapamycin; mTORC, mTOR complex; NRL, neural retina leucine zipper; RAS, rat sarcoma; RAF, rapidly accelerated fibrosarcoma; SEGA, subependymal giant cell astrocytoma; $\mathrm{SHH}$, sonic hedgehog; TSC, tuberous sclerosis complex; WNT, wingless/integrated

${ }^{1}$ Neuroscience and Neurorehabilitation Department, Neurology Unit, Bambino Gesù Children's Hospital, IRCCS, Rome, Italy; ${ }^{2}$ Systems Medicine Department, Child Neurology and Psychiatry Unit, Tor Vergata University Hospital of Rome, Rome, Italy; ${ }^{3}$ Department of Hematology/Oncology and Stem Cell Transplantation, Bambino Gesù Children's Hospital, IRCCS, Rome, Italy; ${ }^{4}$ Department of Neuroscience and Neurorehabilitation, Neurosurgery Unit, Bambino Gesù Children's Hospital, IRCCS, Rome, Italy; ${ }^{5}$ Department of Molecular Medicine, Sapienza University, Rome, Italy; ${ }^{6}$ Center for Life NanoScience@Sapienza, Istituto Italiano di Tecnologia, Rome, Italy; ${ }^{7}$ Department of Laboratories - Pathology Unit Bambino Gesù Children's Hospital, IRCCS, Rome, Italy; ${ }^{8}$ Department of Laboratories, Medical Genetics laboratory, Bambino Gesù Children's Hospital, IRCCS, Rome, Italy; ${ }^{9}$ Neuroradiology Unit, Imaging Department, Bambino Gesù Children's Hospital, IRCCS, Rome, Italy; ${ }^{10}$ Department of Pediatric Science, University of Pavia, Italy; ${ }^{11}$ Department of Pediatrics, "Università Cattolica del Sacro Cuore,", Rome, Italy

Grant sponsor: European Community; Grant number: 602391. Conflict of interest: Nothing to declare.

Romina Moavero and Valentina Folgiero contributed equally to this work.

*Correspondence to: Valentina Folgiero, Department of Hematology/Oncology and Stem Cell Transplantation, Bambino Gesù 
Seizure control was obtained by carbamazepine. Normal psychomotor development was observed thereafter. Molecular genetic analysis on peripheral blood cells, including nextgeneration sequencing and multiplex ligation-dependent probe amplification, revealed no mutations.

At the age of 5 years and 7 months, she presented with torticollis associated with headache, vomiting, and ataxia. MRI showed a large rounded cerebellar lesion, arising from the vermis and occupying the fourth ventricle with secondary hydrocephalus. A second mass was observed in the pituitary peduncle (Fig. 1A).

After endoscopic third ventriculostomy, subtotal resection was performed with residual disease on the floor of the fourth ventricle. Cerebro-spinal fluid sampling confirmed dissemination of disease. A postoperative posterior fossa syndrome was observed from which the patient had completely recovered at 40 days from surgery.

Histology documented a large cell/anaplastic (LC/A) MB (Fig. 1B). Overexpression of NRL (neural retina leucine zipper), NRP3, MAB21L2 (mab-21-like 2), IMPG2 (interphotoreceptor matrix proteoglycan 2), EGFL11 (alias of EYS: eyes shut homolog), and GABRA5 (gamma-aminobutyric acid [GABA] A receptor, alpha 5) was suggestive of a molecular Group $3 \mathrm{MB}$ (Fig. 2A). MYC was not amplified but messenger RNA expression levels of both c-myc and n-myc were higher than in normal cerebellar tissue (Fig. 2B).

Western blot analysis showed strong expression of mTOR and its phosphorylated form (Fig. 2C). No mutations were identified in the MB, thus excluding the presence of TSC1 and TSC2 somatic mutation in the tumor.

The patient was treated with a tailored chemotherapeutic regime based on methotrexate, cyclophosphamide, and carboplatin plus vincristine. Complete remission of disease was obtained and two courses of high-dose thiotepa with autologous peripheral hemopoietic stem cell rescue were administered. Considering the pivotal role of mTOR in the pathogenesis of TSCassociated tumors, off-label treatment with everolimus, a selective inhibitor of mTOR pathway, was started. Radiotherapy was discussed but not performed and the patient is alive and in complete remission of the disease at 17 months from diagnosis. Antiepileptic treatment was gradually stopped without any electroencephalogram (EEG) evidence of residual epileptic activity.

\section{DISCUSSION}

$\mathrm{MB}$ is the most common malignant brain tumor in children and, despite recent treatment advances, approximately $40 \%$ of children experience tumor recurrence and 30\% will die of their disease. Molecular profiling of $\mathrm{MB}$ has recently emerged as a tool for risk stratification with molecular subgroup 3 having the worst prognosis.[1] Group 3 tumors account for $28 \%$ of all MBs, have a high incidence of LC/A histology and are very frequently metastatic. LC/A MB are characterized by c-myc overexpression, which is highly associated with a worse clinical outcome.[1] Our patient presented several poor prognosis indicators, includ-

Children's Hospital, IRCCS, Piazza S. Onofrio 4, 00165 Rome, Italy. E-mail: valentina.folgiero@opbg.net

Received 11 August 2015; Accepted 27 October 2015
A

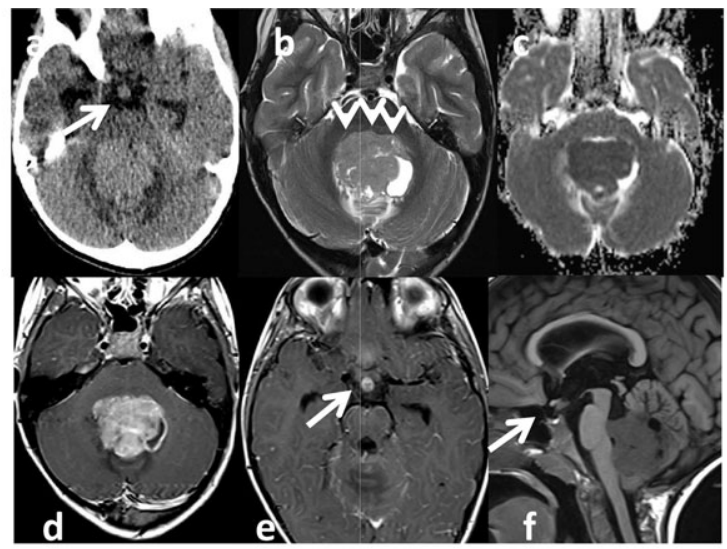

B

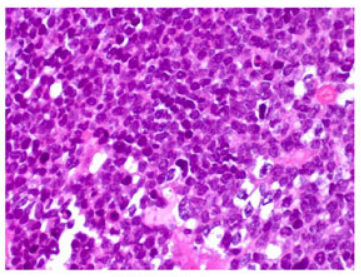

H\&E Stain
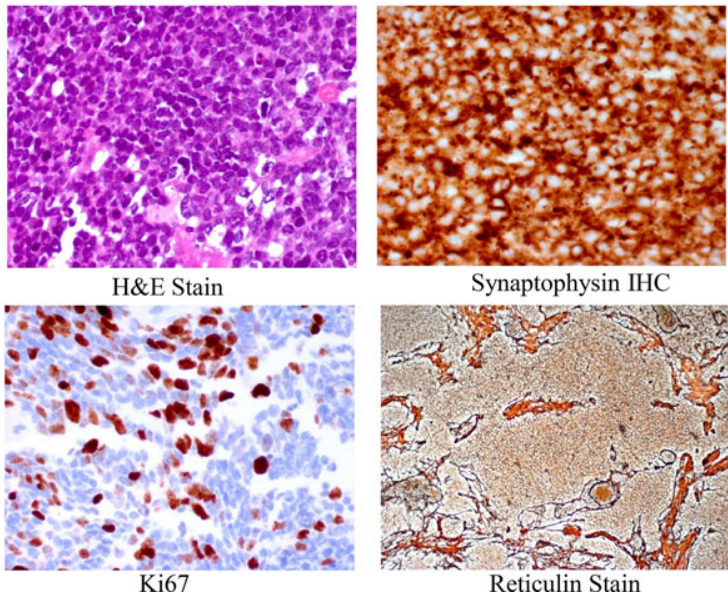

Synaptophysin IHC



Fig. 1. (A) Axial CT scan (a); axial T2-weighted image (b); ADC map (c); Gd-enhanced axial T1-weighted images (d and e); Sagittal T1-weighted image (f). The midline mass is slightly hyperdense to brain on CT scan (a). The lesion is slightly hyperintense on T2-weighted images (b). Diffusion weighted imaging-ADC map (c) showing areas of restricted diffusion due to the high cellularity/high nucleus-cytoplasm ratio. Marked and inhomogeneous enhancement is seen following gadolinium administration (d). Axial image shows thick neoplastic infiltration of the fourth ventricular floor (arrow heads, b). The sagittal T1-weighted image (d) shows that the hypointense lesion arises from the vermis and fills the fourth ventricle. There is gross dilatation of the superior part of the fourth ventricle and supratentorial hydrocephalus. Note a secondary lesion at the level of the infundibulum (arrow; a, e, and d), and downward tonsillar displacement (f). (B) Highly cellular neoplasia composed of round small/medium-sized cells, with hyperchromatic nuclei and scanty cytoplasm. Nuclear polymetrism and atypical mitoses are evident (H\&E stain); diffuse pattern of synaptophysin positivity of neoplastic cells; high proliferation rate (Ki67 IHC stain). Reticulin stain revealed/showed a diffuse pattern of growth without pale area formation or nodularity features.

ing LC/A histology, molecular subgroup 3, metastatic disease, and residual disease after surgery.

Although MBs are more often sporadic, they can be found in different syndromic conditions such as Gorlin syndrome, familial adenomatous polyposis, Fanconi anemia, RASopathies, Rubinstein-Taybi syndrome, Mowat-Wilson syndrome, and Turner syndrome.[8-12] The most frequent CNS tumors in TSC 
A

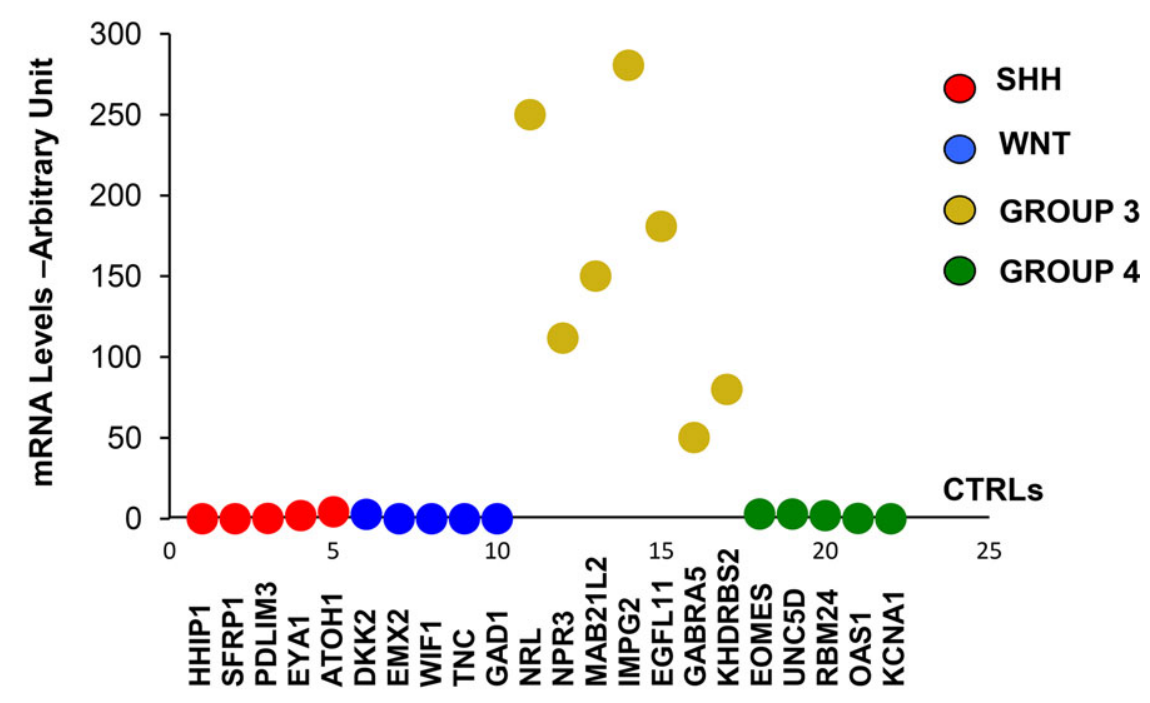

B

C
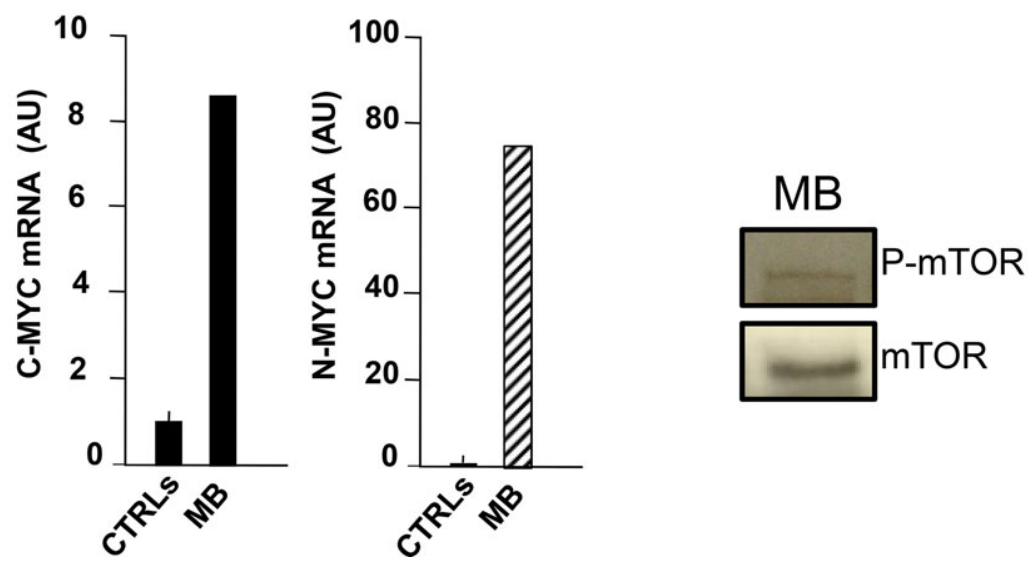

Fig. 2. (A) MB molecular characterization and c-MYC expression-messenger RNA (mRNA) levels of the indicated genes in MB compared to normal cerebellum (average, $n=8$ ) as control (CTRLs). Genes are grouped and depicted in different colors, depending on the molecular subgroup, which are identified as SHH, WNT, Group 3, and Group 4. The values of relative quantification are expressed in linear scale arbitrary units. (B) Histograms showing mRNA expression levels of c-MYC (left panel) and n-MYC (right panel) in MB compared to normal cerebellum (average, $\mathrm{n}=8$ ) as CTRLs. (C) MB tissue samples were lysed in Ripa buffer and resolved by $8 \%$ sodium dodecyl sulphate-polyacrylamide gel electrophoresis (SDS-PAGE). Western blotting anti-P-mTOR was performed to evaluate mTOR activation.

are subependymal giant cell astrocytomas (SEGA), CNS malignancies that are exceedingly rare and limited to glioblastoma multiforme.[6,7] To our knowledge, this is the first report of MB associated with TSC.

As regards any tumor predisposing condition, we speculate that the genetic substrate of TSC might have played a role in the onset of the MB in our patient. TSC commonly results from mutations in the $T S C 1$ or TSC2 genes encoding hamartin and tuberin, respectively.[13] Ten to 25 percent of patients affected by TSC have no mutation identifiable by available genetic testing, and therefore in these cases a definite diagnosis is made using clinical diagnostic criteria.[7]

Independent of mutational status, hamartin/tuberin dysfunction is a central event in TSC pathogenesis, leading to overactivation of the mTOR pathway that is responsible for the forma- tion of hamartomas and malignancies typical of TSC.[14-16] Notably, TSC2 mutation has also been reported in MB samples and, more recently, TSC1 mutation has been detected in Group 3 MB.[2,17] RAS/RAF-mediated m-TORC activation has also been described in $\mathrm{MB}$ with resulting $\mathrm{c}-\mathrm{MYC}$ translational regulation conditioning cell growth and proliferation.[18,19]

Our patient showed normal expression of TSC1 and TSC2 both on blood samples and tumor tissue. However, mTOR was activated as shown by its phosphorylated status, and c-MYC was overexpressed with no evidence of amplification.

We hypothesize a key role for TSC1/TSC2-independent activation of $\mathrm{mTOR}$ in the pathogenesis of both TSC and MB. Of note, our patient showed a surprising sensitivity to chemotherapy with complete remission of disease after only two treatment courses without radiation therapy. Beginning treatment early 
Moavero et al.

after surgery (15 days), when the blood-brain barrier had not recovered, might have played a role in maximizing response to treatment. Despite the well-documented role of radiation in the treatment of $\mathrm{MB}$, we decided to omit it considering the dramatic response to chemotherapy and the risk of secondary malignancies due to her cancer predisposition syndrome.

Based on the previous reports for SEGAs, our child received a dose of $3 \mathrm{mg} / \mathrm{m}^{2}$ of everolimus (range $5-15 \mathrm{ng} / \mathrm{ml}$ ), and we speculate that this treatment might have contributed to remission of disease. Moreover, although no specific effect on epilepsy can be inferred as clinical seizures had not been observed for a long time before tumor diagnosis, our patient had a complete normalization of her EEG 6 months after treatment initiation.[20]

In conclusion, patients affected by TSC should be considered at risk for CNS malignancies, and the posterior fossa should be considered in all neuroradiologic examinations. MB associated with TSC may have a different behavior from comparable sporadic $\mathrm{MB}$ with a more favorable outcome. Indications for radiation therapy should be considered on an individual basis, especially in the presence of a dramatic response to chemotherapy. Considering the pivotal role of mTOR activation in TSC, it should be tested in all associated malignancies to guide targeted therapy.

\section{ACKNOWLEDGMENTS}

We are grateful to the child's parents, who gave their informed consent for publication. IRB approval has been obtained. RM and PC received funding from the European Community's Seventh Framework Programme (FP7/2007-2013) under grant agreement no. 602391 (www.epistop.eu). The authors are also grateful to the Association "Per Un Sorriso in Più ONLUS."

AM, RM, AC, PC, FV, MV, SGC, and FL clinically followed the patient. AM, AT, FDC, and FL carried out pathologic assessments. EM, AP, EF, and VF performed the molecular studies and FRL performed the genetic evaluations.

\section{REFERENCES}

1. Li, KK, Lau KM, Ng HK. Signaling pathway and molecular subgroups of medulloblastoma. Int J Clin Exp Pathol 2013;6:1211-1222.

2. Northcott PA, Shih DJ, Peacock J, Garzia L, Morrissy AS, Zichner T, Stütz AM, Korshunov A,
Reimand J, Schumacher SE, Beroukhim R, Ellison DW, Marshall CR, Lionel AC, Mack S, Dubuc A, Yao Y, Ramaswamy V, Luu B, Rolider A, Cavalli FM, Wang X, Remke M, Wu X, Chiu RY, Chu A, Chuah E, Corbett RD, Hoad GR, Jackman SD, Li Y, Lo A, Mungall KL, Nip KM, Qian JQ, Raymond AG, Thiessen NT, Varhol RJ, Birol I, Moore RA, Mungall AJ, Holt R, Kawauchi D, Roussel MF, Kool M, Jones DT, Witt H, Fernandez-L A, Kenney AM, Wechsler-Reya RJ, Dirks P, Aviv T, Grajkowska WA, Perek-Polnik M, Haberler CC, Delattre O, Reynaud SS, Doz FF, PernetFattet SS, Cho BK, Kim SK, Wang KC, Scheurlen W, Eberhart CG, Fèvre-Montange M, Jouvet A, Pollack IF, Fan X, Muraszko KM, Gillespie GY, Di Rocco C, Massimi L, Michiels EM, Kloosterhof NK, French PJ, Kros JM, Olson JM, Ellenbogen RG, Zitterbart K, Kren L, Thompson RC, Cooper MK, Lach B, McLendon RE, Bigner DD, Fontebasso A, Albrecht S, Jabado N, Lindsey JC, Bailey S, Gupta N, Weiss WA, Bognár L, Klekner A, Van Meter TE, Kumabe T, Tominaga T, Elbabaa SK, Leonard JR, Rubin JB, Liau LM, Van Meir EG, Fouladi M, Nakamura H, Cinalli G, Garami M, Hauser P, Saad AG, Iolascon A, Jung S, Carlotti CG, Vibhakar R, Ra YS, Robinson S, Zollo M, Faria CC, Chan JA, Levy ML, Sorensen PH, Meyerson M, Pomeroy SL, Cho YJ, Bader GD, Tabori U, Hawkins CE, Bouffet E, Scherer SW, Rutka JT, Malkin D, Clifford SC, Jones SJ, Korbel JO, Pfister SM, Marra MA, Taylor MD. Subgroup-specific structural variation across 1,000 medulloblastoma genomes. Nature 2012;488:49-56.

3. Curatolo P, Bombardieri R, Jozwiak S. tuberous sclerosis. Lancet 2008:372:657-668.

4. Tee AR, Fingar DC, Manning BD, Kwiatkowski DJ, Cantley LC, Blenis J. Tuberous sclerosis complex-1 and -2 gene products function together to inhibit mammalian target of rapamycin (mTOR)-mediated downstream signaling. Proc Natl Acad Sci USA 2002;99:13571-13576.

5. Bathia B, Nahlé Z, Kenney AM. Double trouble: when sonic hedgehog signaling meets TSC inactivation. Cell Cycle 2010;9:456-459.

6. Reyes D, Prayson R. Glioblastoma in the setting of tuberous sclerosis. J Clin Neurosci 2015;22:907908.

7. Northrup H, Krueger DA. International Tuberous Sclerosis Complex Consensus. Tuberous sclerosis complex diagnostic criteria update: Recommendations of the 2012 international tuberous sclerosis complex consensus conference. Pediatr Neurol 2013;49:243-254.

8. Bourdeaut F, Miquel C, Richer W, Grill J, Zerah M, Grison C, Pierron G, Amiel J, Krucker C, Radvanyi F, Brugieres L, Delattre O. Rubinstein-Taybi syndrome predisposing to non-WNT, nonSHH, group 3 medulloblastoma. Pediatr Blood Cancer 2014;61:383-386.

9. Miele E, Mastronuzzi A, Po A, Carai A, Alfano V, Serra A, Colafati GS, Strocchio L, Antonelli M, Buttarelli FR, Zani M, Ferraro S, Buffone A, Vacca A, Screpanti I, Giangaspero F, Giannini G, Locatelli F, Ferretti E. Characterization of medulloblastoma in Fanconi Anemia: A novel mutation in the BRCA2 gene and SHH molecular subgroup. Biomarker Res 2015;3:13; doi:10.1186/s40364015-0038-z.

10. Pendergrass TW, Fraumeni JF Jr. Letter: Brain tumors in sibs, one with the Turner syndrome. J Pediatr 1974;85:875

11. Rankin J, Short J, Turnpenny P, Castle B, Hanemann CO. Medulloblastoma in a patient with the PTPN11 p.Thr468Met mutation. Am J Med Genet A 2013;161A:2027-2029.

12. Valera ET, Ferraz ST, Brassesco MS, Zhen X, Shen Y, dos Santos AC, Neder L, Oliveira RS, Scrideli CA, Tone LG. Mowat-Wilson syndrome: the first report of an association with central nervous system tumors. Childs Nerv Syst 2013;29:2151-2155.

13. van Slegtenhorst M, de Hoogt R, Hermans C, Nellist M, Janssen B, Verhoef S, Lindhout D, van den.Ouwland A, Halley D, Young J, Burley M, Jeremiah S, Woodward K, Nahmias J, Fox M, Ekong R, Osborne J, Wolfe J, Povey S, Snell RG, Cheadle JP, Jones AC, Tachataki M, Ravine D, Sampson JR, Reeve MP, Richardson P, Wilme F, Munro C, Hawkins TL, Sepp T, Ali JB, Ward S, Green AJ, Yates JR, Kwiatkowska J, Henske EP, Short MP, Haines JH, Jozwiak S, Kwiatkowski DJ. Identification of the tuberous sclerosis gene TSC1 on chromosome 9q34. Science 1997;277:805808 .

14. Jozwiak J. Hamartin and tuberin: working together for tumour suppression. Int J Cancer 2006;118:1-5

15. Napolioni V, Moavero R, Curatolo P. Recent advances in neurobiology of tuberous sclerosis complex. Brain Dev 2009;31:104-113.

16. Cantley LC. The phosphoinositide 3-kinase pathway. Science 2002;296:1655-1657.

17. Przkora R, Meyer-Puttlitz B, Schmitt O, Berthold F, Nothen M, Krauss J, Tonn JC, von Deimling A, Wiestler OD, Pietsch T. Analysis of the TSC2 gene in human medulloblastoma. Acta Neuropathol 2001;102:380-384.

18. MacDonald TJ, Aguilera D,Castellino RC. The rationale for targeted therapies in medulloblastoma. Neuro Oncol 2014:16:9-20.

19. Sodi VL, Khaku S, Krutilina R, Schwab LP, Vocadlo DJ, Seagroves TN, Reginato MJ. mTOR/MYC axis regulates $\mathrm{O}-\mathrm{GlcNAc}$ transferase expression and $\mathrm{O}-\mathrm{GlcN}$ acylation in breast cancer. Mol Cancer Res 2015;13:923-933.

20. Franz DN, Agricola K, Mays M, Tudor C, Care MM, Holland-Bouley K, Berkowitz N, Miao S, Peyrard S, Krueger DA. Everolimus for subependymal giant cell astrocytoma: 5-year final analysis. Ann Neurol 2015; doi:10.1002/ana24523. 